\title{
Development of Manufacturing Efficiency using Industry Cluster and Invention Method Application: Case Study Machetes Production Group in Nakhon Phanom Province Thailand
}

\author{
Supachai PRAINETR ${ }^{1, *}$, Natchanun PRAINETR ${ }^{2}$ and Sumitchai KANHAKHUN ${ }^{3}$ \\ ${ }^{I}$ Department of Industrial Electrical Technology, Faculty of Industrial Electrical Technology of Nakhon \\ Phanom University, Nakhon Phanom 48000, Thailand \\ ${ }^{2}$ Department of General Science Education Thadphanom College of Nakhon Phanom University, \\ Nakhon Phanom 48110, Thailand \\ ${ }^{3}$ Nawa College of Nakhon Phanom University, Nakhon Phanom 48000, Thailand
}

('Corresponding author's e-mail: prainetr@npu.ac.th)

Received: 10 April 2018, Revised: 13 December 2019, Accepted: 16 January 2020

\begin{abstract}
Development small and medium enterprise (SME) of Thailand have been important for generating incomes and developing community-based business of Thai people. This paper proposes a development efficiency of machetes production in the Ban $\mathrm{Na}$ Thon community of Nakhon Phanom province. This strategy is apply by the industrial cluster method and development an innovation. The methodology consisted of 4 steps. The first study involved a study context of community, coordination with people, meetings and recording primary data with interviews and questionnaires. The research participants were people in the community in Nakhon Phanom University. The performance of the proposed development and design furnace can be controlled by proportional integral derivative (PID) at the temperatures ranging from 0 to $1,200{ }^{\circ} \mathrm{C}$; the development the hardening tub can be controlled by the temperature of water in the hardening process, development of grinding machine. Results confirm that this development research has an efficiency more than conventional method.
\end{abstract}

Keywords: Industry cluster, Invention, Machetes production, Nakhon Phanom Thailand

\section{Introduction}

Machetes knife production of Ban Nathon That Phanom district in Nakhon Phanom province Thailand has been conserved for the period of 92 years. The original knife production was derived from France Roman Catholic priest, who was trained to create knife with people in rural community. Initially, the knife was used for agriculture, created by classical method, involving the materials such as iron, sintering furnace made of clay, fuel with charcoal, and manual air flow pump. The knife production has been good in quality strong, non-expensive and popular in Nakhon Phanom, Sakon Nakhon, Mukdahan and Kalasin province, including in Khammouane province, Laos. Moreover, machete product has been reliable which has increased the order from customers. Therefore, production will require a lot of labors and machine to support the work. However, the operation in production group have been carried out for the household industry. The development has been slow for the industry, because of a weak of management system $[1,2]$.

During the past few years, small and medium economic (SME) of Thailand has concentrated on the development of the competitiveness of enterprises. In the form of the clusters, the authorities in the country include both the public and private sectors. The cluster concept can develop capacity in areas, such as manufacturing, marketing and management, in which the members have ability to race higher [2]. 
Division of Industrial Economics Office of Thailand has studied the development and supported the silk industry of the northeastern region in Thailand, which for the growth of the silk industry, this work found that the rate of a change in sales income, cost and profit was at $1-3 \%$ when compared with the operation in the previous year. After analyzing a model of the growth of the silk industry in the northeastern region, we found that TQM, administrative and marketing strategies affected the growth of the silk industry in the northeastern region. The model correlated with data and validity because the square multiple correlation $\left(\mathrm{R}^{2}\right)$ was $42.3 \%$ which was more than $40 \%$.

This paper examines the development of manufacturing machetes production group using Industry cluster method application which the activity consists of the brain storming of stakeholder for development the efficiency of machinery in the manufacturing process. This paper is organized as follows: Section 2 presents the material and methods cluster concept principle and research framework are described in this section, followed by the experimental of innovation machine and result in Section 3. Finally, the paper ends with the discussions and conclusions.

\section{Materials and methods}

Research framework

This study, fist, established the research framework. Figure 1 shows the concept of this research.

\begin{tabular}{|c|c|c|c|}
\hline \begin{tabular}{l}
\multicolumn{1}{c}{ Input } \\
-Data context of the \\
Machete production \\
community group \\
- Data of machete group \\
- Data of industry \\
management \\
- Statement problem of \\
machete manufacturing \\
process
\end{tabular} & $\begin{array}{l}\quad \text { Process } \\
\text { - The concept of the } \\
\text { industry cluster } \\
\text { management } \\
\text { - Application the } \\
\text { innovation } \\
\text { - Burner furnace } \\
\text { - Grinding machine } \\
\text { - Hardening machete }\end{array}$ & $\begin{array}{l}\text { Output } \\
\text {-The Innovation to } \\
\text { solve problem in the } \\
\text { machete process } \\
\text { - Comparison result } \\
\text { between before and } \\
\text { after development }\end{array}$ & $\begin{array}{l}\quad \text { Outcome } \\
\text { - Efficiency of } \\
\text { development } \\
\text { industry in the } \\
\text { machete product } \\
\text { community }\end{array}$ \\
\hline
\end{tabular}

Figure 1 Research framework.

Figure 1 shows diagram of research framework consist, $1^{\text {st }}$ block is the context and detail status and statement of the community to select the method problem solution, $2^{\text {nd }}$ block is the methodology while such as 2 methods are the industry cluster, application the innovation development and finally is outcome of the research is development efficiency industry of machete group in the rural, innovation to solved problem of machete manufacturing process and compare the result between before and after of development [4-7].

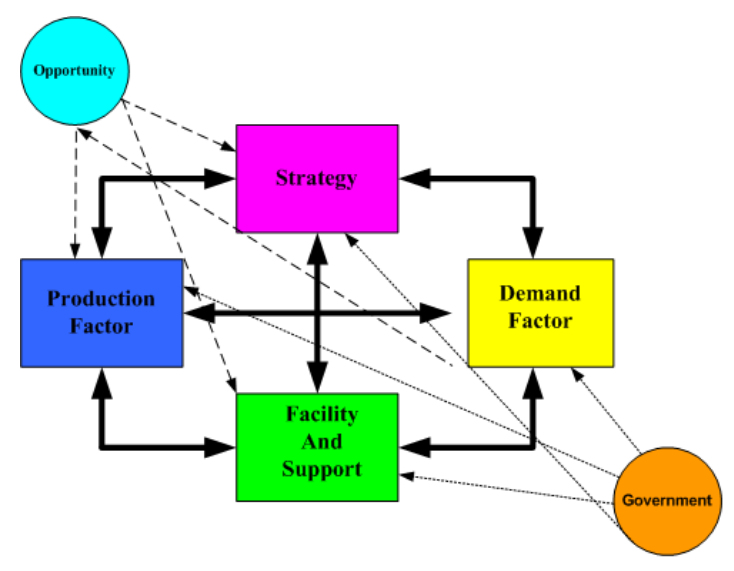

Figure 2 Diamond model. 
Figure 2 shows diamond model by the cluster concept, classify 4 variable consist strategy, production factor, facility, demand factor, and 2 variable for supporting were government and opportunity in the industry.

\section{Concept in selection cluster}

According the conception selected cluster of JICA model, it will be evaluated by score use evaluated by scoring method 100 points and consideration based on 4 main topics as follows.

1. A is main industry

2. B growth trend industry

3. C The existence of the Business Development Unit

4. D The interests and intentions of people in the area

JICA will focus on the industry with the highest potential first.

\section{Cluster concept of community}

Traditional developed industry cluster in Thailand has a trend to increase efficiency and application in the industry community such as ceramic production, local textile, which past activitied showed the participant development in community industry. As well, the production of industrial machete has brought the concept of cluster management to improve production by innovation technology application that can potentially solve the problem energy consumption and support for work safety.

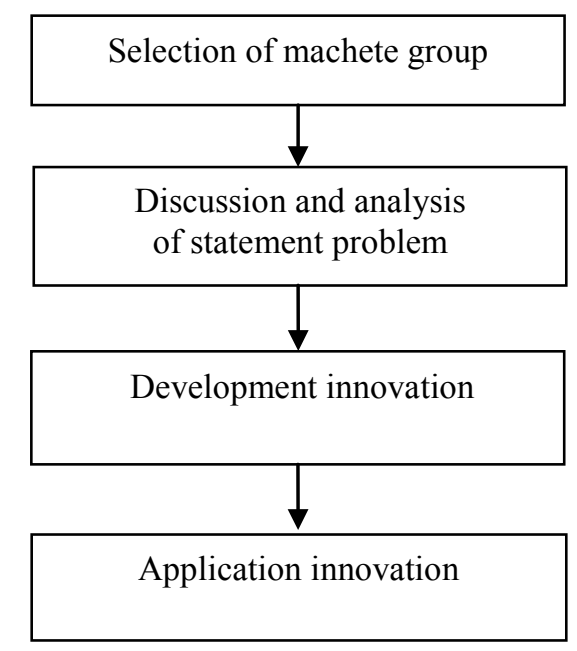

Figure 3 Diagram cluster method of machete community Nathon Thailand.

Figure 3 shows the development diagram of machete product by cluster method and creation innovation for edit problem. In $1^{\text {st }}$ block diagram is a selection population, $2^{\text {nd }}$ block is analysis method and discuss problem used the concept of diamond model and the end block is an innovation for solving production problem has as follow.

1. Development of furnace by the application of PID control method to solve the problem of unstable temperature.

2. Development of hardening tub for the hardening process by the application of cooling down with radiator, in which the temperature can be controlled using PID.

3. Development of grinding machine which can be controlled by the speed of the machine using the inverter control. 

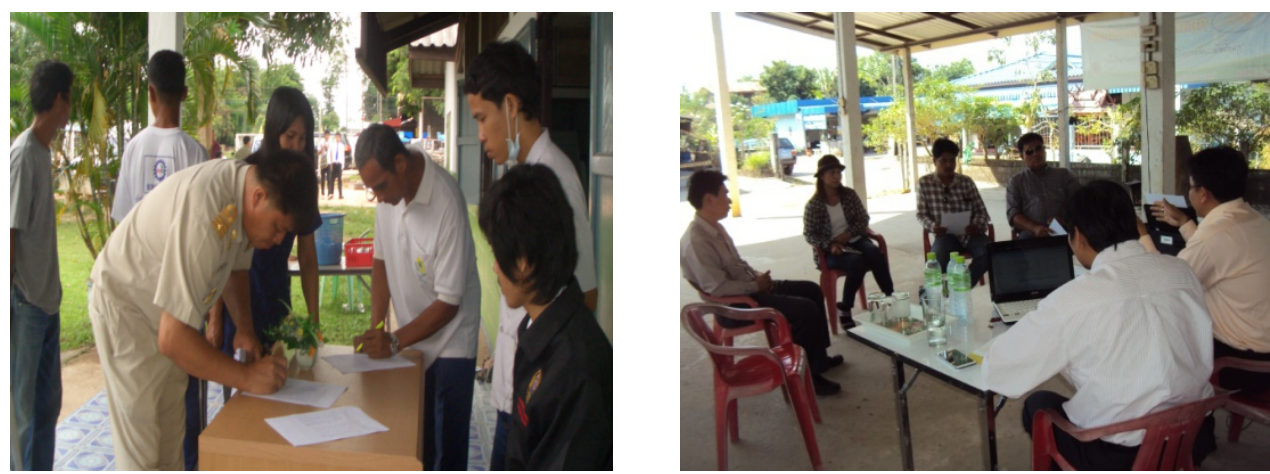

Figure 4 Activity under cluster method of machete production in Nakhon Phanom Thailand.

Figure 4 shows the activity in the $1^{\text {st }}$ was public about development project via cluster concept, next step were to register of people in machelete knife group to interest in co-project, mini seminar focus group and participant in working area with develop process and reduce weak of production process, increasing quality of machelete knife, energy conservation in production process, the participant between management of knife group (SME), The facility industry organizer of Thailand and Nakhon Phanom University, all activity to support in development the industry in rural area base on the cluster concept.

\section{Manufacturing process of machete production}

This research aims to resolve the problem in production of machetes in Ban $\mathrm{Na}$ Thon community, Nakhon Phanom, and the design methodology with techniques in the industry and knowledge management from the industry cluster. The process of production machetes is as follows.

Figure 5(a) Leaf spring steel is a material for creating machete, Figure 5(b) cutting leaf spring steel is $3 \mathrm{~cm}$ in width and $30 \mathrm{~cm}$ in length. Figure 5(c) leaf spring steel has a shape ready for forging process. Figure 5(d) shows the making process the machete to use the classic furnace and charcoal energy, which its heating energy loss, power consumption and the furnace cannot control temperature so the development furnace to save energy and can be controlled at the temperatures of $0-1,200{ }^{\circ} \mathrm{C}$. Figures 5(e) and 5(g) shows grinding used cycle stone and drive the conveyor by motor, but its danger by fire spark on the grinding and cannot control speed of motor to optimization so the development handgrip and grad for safety and can be speed control motor pending $0-1,500 \mathrm{rpm}$ in order to safety in the working. Figure 5(h) shows hardening the machete used sink water its cannot control temperature at sink water effect to blade breakage, so the development the sink water for the hardening can be temperature control and water loop control to release heat by boiler. All 3 processes are important in the process of machetes manufacturing process. 


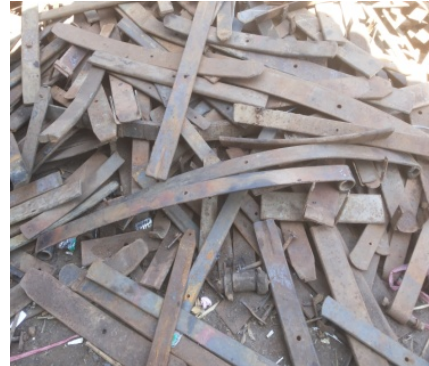

(a)

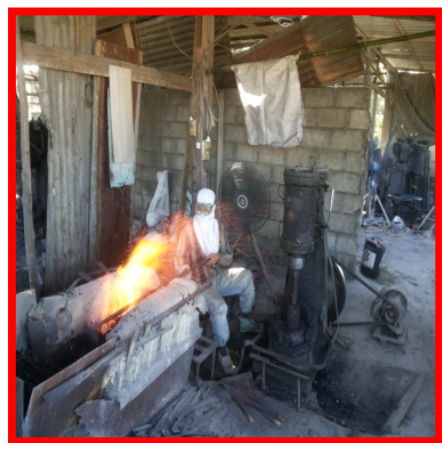

(d)

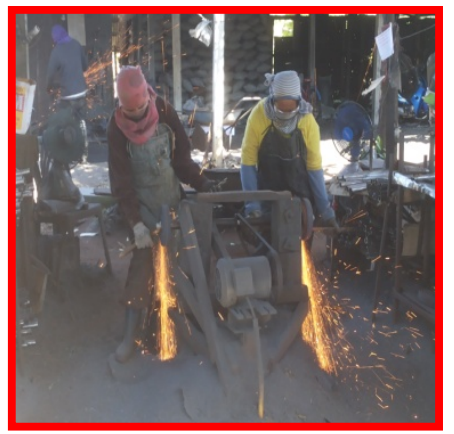

$(\mathrm{g})$

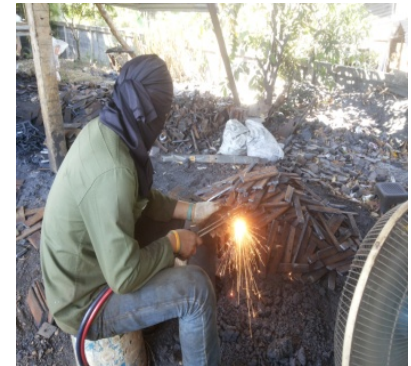

(b)

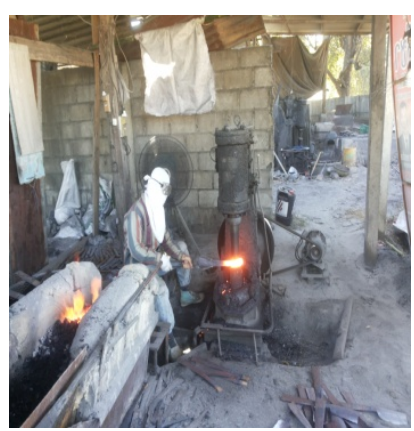

(e)

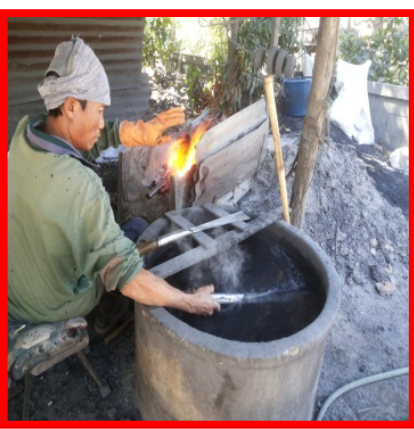

(h)

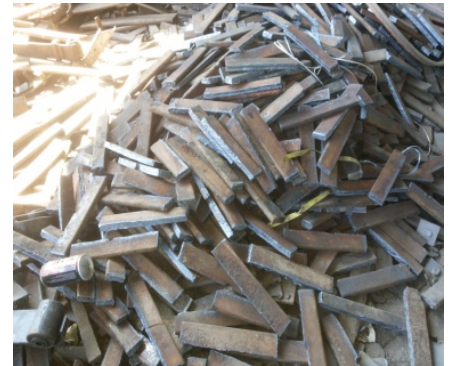

(c)

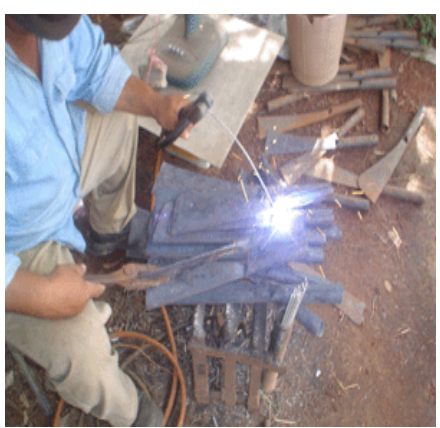

(f)

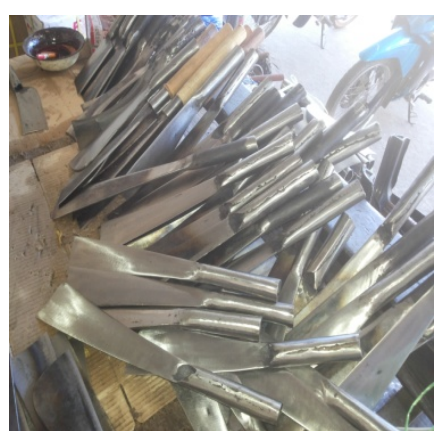

(i)

Figure 5 Process of production machetes; (a) Leaf spring steel, (b) Cutting steel with LPG gas, (c) Steel to make the machete (d) Classic furnace, (e) Forging machete with machine, (f) Welding handgrip machete, (g) Grinding, (h) hardening process, (i) The machetes the production.

\section{The concepts of troubleshoot}

From the statement problem of the machetes manufacturing process, we have applied the engineering knowledge to solve the problem about the energy loss of classical furnace. The knowhow of engineering application, which the PID control theory, this concept can be applied by controlling the temperature furnace to reach stability $[8,9]$. 


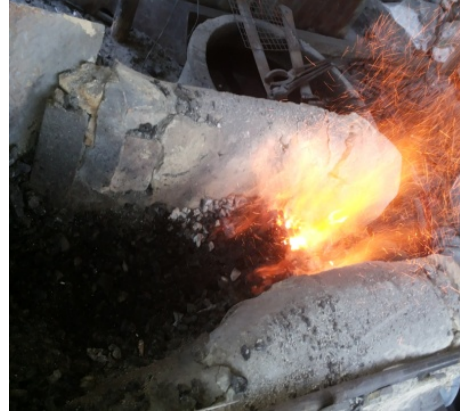

(a)

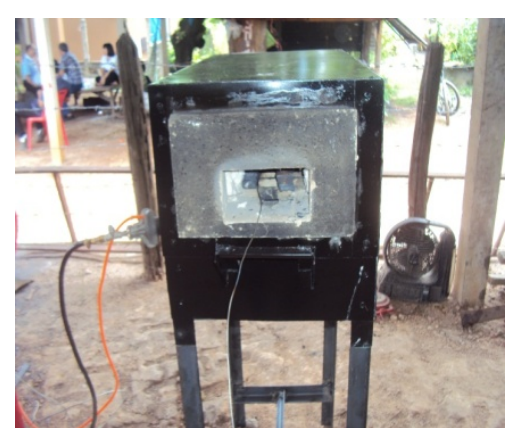

(b)

Figure 6 (a) The furnace between classic furnace, (b) The development new furnace.

Figure 6(a) shows the classical furnace before the development, the classical furnace has the frame wide $60 \mathrm{~cm}$ long $100 \mathrm{~cm}$ high $50 \mathrm{~cm}$ which are simply created by using clay. However, furnace has more heating loss caused by the wall radiation, the heating loss energy, and the consumption energy, which cannot control the temperature. Figure 6(b) shows the development new furnace, by design the structure has frame $40 \mathrm{~cm}$ long $70 \mathrm{~cm}$ high $100 \mathrm{~cm}$, the wall furnace created by refractory brick SK30 has heat resistance $1,300{ }^{\circ} \mathrm{C}$ and control the $\mathrm{LPG}$ gas fuel and temperature control by proportional integral derivative (PID) it can be controlled at the temperatures of 0 - 1,200 Moreover, the PID controller provides the most stable and accurate control, and is ideal for systems with a relatively small mass and for those systems that rapidly react to energy changes in the process.

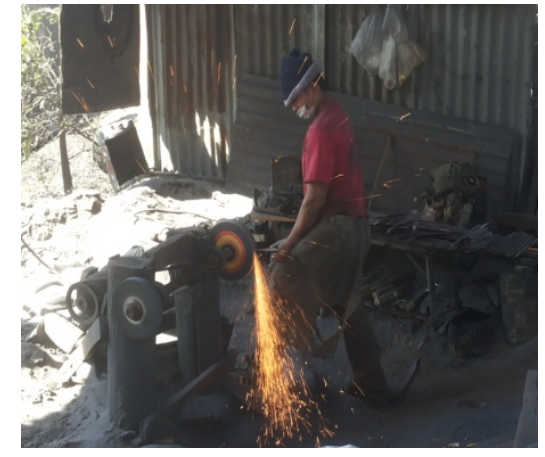

(a)

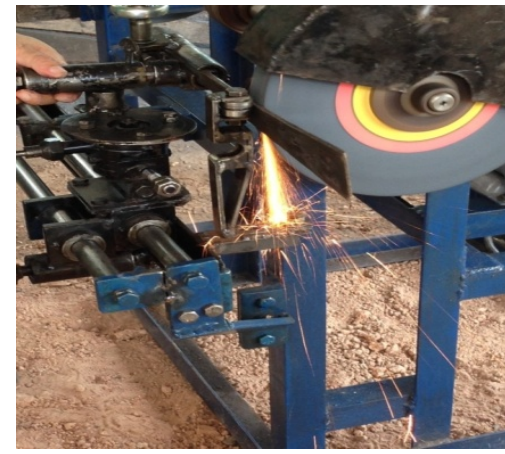

(b)

Figure 7 The Grinding machine between before and after development.

Figure 7(a) shows the classical grinding machine has structure are simple, but it has dangerous by fire spark and not protection. Figure 7(b) shows the new grinding machine has wide $100 \mathrm{~cm}$ long $90 \mathrm{~cm}$ high $100 \mathrm{~cm}$, the grind stone have diameter $30 \mathrm{~cm}$ and speed control pending $0-1,500 \mathrm{rpm}$ with the inverter control. 


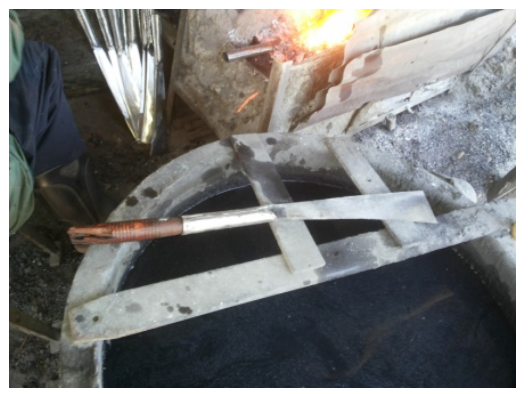

(a)

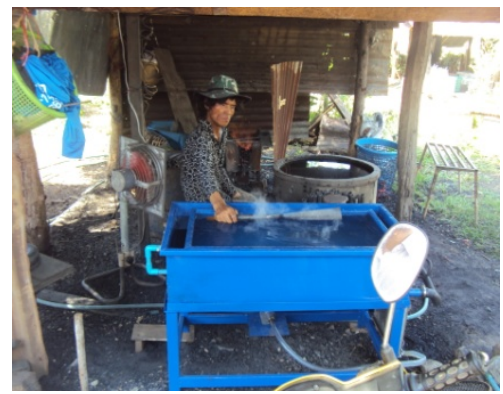

(b)

Figure 8 The basin hardening between before and after development.

Figure 8(a) shows the classical basin machete of hardening created with cement circular shape and has diameter $70 \mathrm{~cm}$ high $60 \mathrm{~cm}$, but it could not release heat of water in the hardening process. Figure 8(b) shows new basin that has wide $50 \mathrm{~cm}$ long $100 \mathrm{~cm}$ high $70 \mathrm{~cm}$ and could release a heat of water by the boiler which cooling has stability. This method could improve efficiency in the machete hardening process $[10,11]$.

\section{Results and discussion}

In improvement of machete manufacturing process in Nathon community Thailand with developed the innovation tool as, furnace, grinding machine and basin hardening. Experimented by the leaf spring SAE 9260, amount 5 samples compare between the machete non hardening and past develop process, by the burning with LPG gas pending $900-1,200{ }^{\circ} \mathrm{C}$, holding time 1, 2, 4, 6 min in hardening process. The harness to measure with micro harness and the result are showed in the following table.

Table 1 Results of the experiment in holding time and hardness by tool development.

\begin{tabular}{|c|c|c|c|c|}
\hline \multirow{2}{*}{ Sample } & \multicolumn{4}{|c|}{ Holding time, Harness (HRC) } \\
\hline & $1 \mathrm{~min}$ & $2 \min$ & $4 \mathrm{~min}$ & $6 \mathrm{~min}$ \\
\hline 1 & 53.8 & 57.8 & 52.8 & 52.2 \\
\hline 2 & 57.3 & 58.4 & 55.6 & 55.7 \\
\hline 3 & 57.7 & 58.5 & 55.3 & 55.6 \\
\hline 4 & 56.8 & 57.8 & 55.1 & 55.4 \\
\hline 5 & 55.9 & 56.4 & 54.5 & 53.8 \\
\hline HRC. mean & 56.3 & 57.78 & 54.66 & 54.54 \\
\hline
\end{tabular}

Table 2 Comparing economic costs between the before process and after development.

\begin{tabular}{lcccc}
\hline \multirow{2}{*}{ Tool development } & \multicolumn{2}{c}{ Time working $(\mathbf{m i n}) /$ piece } & \multicolumn{2}{c}{ Cost economy (THB.)/piece } \\
\cline { 2 - 5 } & Before & After & Before & After \\
\hline Burning furnace & 9 & 5 & 1.50 & 0.5 \\
Grinding machine & 7.5 & 2.5 & 5.8 & 2.5 \\
Basin hardening & 5 & 2 & 7 & 3.5 \\
\hline
\end{tabular}




\section{Conclusions}

This paper has showed participation in machete manufacturing community of Nakhon Phanom province Thailand which under cluster concept and via created meeting activity and mini seminar for discussion topic main problem in industry process. We have an idea to develop tools and process in the industry and configuration schedule work time at 12 mounts and experimented at Nakhon Phanom University laboratory with testing equipment something in the rural factory. The result shows that and comparison between before and after in development. It has been confirmed that the application of the cluster concept is important for sustainable development for industrial in rural. Moreover, it can be used to manage the resource more effectively, shorten work-hour, reduce cost and enhance work.

\section{Acknowledgements}

The author would like to thank research scholarship from Nakhon Phanom University and Northeast Support Industrial Center.

\section{References}

[1] S Prainetr and N Prainetr. Development and onservative of pressing michelet classical culture base on participation and knowledge management: Case study Nathon Community Thatphanom district Nakhon Phanom province. Scholarship report paper by Ministry of Culture, Thailand, 2013.

[2] S Prainetr and N Prainetr. The development of programmable logic controller system for control machete thump machine application in the Nathon community Thatphanom district Nakhon Phanom province. Scholarship report paper by Ministry of Science and Technology, Thailand, 2012.

[3] Y Lai, M Hsu, F Lin, Y Chen and Y Lin. The effects of industry cluster knowledge management on innovation performance. J. Bus. Res. 2014; 67, 734-9.

[4] Z He, S Xu, W Shen, R Long and H Yang. Overview of the development of the Chinese Jiangsu coastal wind-power industry cluster. Renew. Sust. Energ. Rev. 2016; 57, 59-71.

[5] MS Hsu and F Lin. The developing strategy of green energy industry cluster a case study of the solar photoelectric industry in Taiwan. Procedia Soc. Behav. Sci. 2012; 40, 165-73.

[6] Sutikno and MSW Suliswanto. The development of manufacturing industry cluster as an effort of economic improvement expansion in East Java. Procedia Soc. Behav. Sci. 2015; 211, 992-8.

[7] J Zheng and R Chan. The impact of creative industry clusters on cultural and creative industry development in Shanghai. City Cult. Soc. 2014; 5, 9-22.

[8] AM Paramonov. Heating furnaces efficiency improvement. Procedia Eng. 2015; 113, 181-5.

[9] D Zhenhai and S Lianyun. Design of temperature controller for heating furnace in oil field. Phys. Procedia 2012; 24, 2083-8.

[10] HS Yoon, ES Kim, MS Kim, JY Lee, GB Lee and SH Ahn. Towards greener machine tools: A review on energy saving strategies and technologies. Renew Sust. Energ. Rev. 2015; 48, 870-91.

[11] P Karban and M Donatova. Continual induction hardening of steel bodies. Math. Comput. Simulat. $2010 ; 80,1771-82$. 